\title{
Pharmacological Effect of Endothelin, an Endothelium-derived Vasoconstrictive Peptide, on Canine Basilar Arteries
}

\author{
Tadayoshi NAKAGOMI, Katsuhisa IDE, Kenta YAMAKawa, Tomio SASAKI, \\ Hiroki KURIHARA*, Isamu SAITO and Kintomo TAKAKURA \\ Department of Neurosurgery and ${ }^{*}$ Third Department of Internal Medicine, \\ Faculty of Medicine, University of Tokyo, Tokyo
}

\begin{abstract}
The purpose of this study was to evaluate the constrictive effect of endothelin, a peptide vasoconstrictor derived from endothelium, on canine basilar artery. Constriction was measured by an isometric tension recording method. Endothelin induced prolonged contraction of canine basilar artery in a dosedependent fashion, the estimated concentration at $50 \%$ contraction being $(2.1 \pm 0.5) \times 10^{-9} \mathrm{M}$ (mean \pm SEM). Removal of endothelium significantly augmented the arterial response to endothelin. In $\mathrm{Ca}^{+}$-free medium no contractile response was elicited at $10^{-8} \mathrm{M}$ endothelin. Papaverine $\left(10^{-4} \mathrm{M}\right)$ and nicardipine $\left(10^{-8} \mathrm{M}\right)$, a calcium channel blocker, almost completely inhibited the contraction induced by $10^{-8} \mathrm{M}$ endothelin. Pretreatment with nicardipine $\left(10^{-8}-10^{-6} \mathrm{M}\right)$ also significantly suppressed the response to endothelin. Acetylcholine $\left(10^{-7}-10^{-4} \mathrm{M}\right)$, adenosine triphosphate $\left(10^{-7}-10^{-5} \mathrm{M}\right)$, and thrombin $(0.1$ and $1.0 \mathrm{U} / \mathrm{ml})$ dose-dependently inhibited contraction of canine basilar artery in response to $3 \times 10^{-9} \mathrm{M}$ endothelin. These results show that endothelin has a potent constrictive effect on canine basilar artery and suggest that this substance may play an important role in the pathogenesis of vasospasm following subarachnoid hemorrhage.
\end{abstract}

Key words: endothelin, subarachnoid hemorrhage, cerebral vasospasm, canine basilar artery

\section{Introduction}

In 1980, Furchgott and Zawadzki ${ }^{14)}$ demonstrated the role of endothelium in the relaxation of isolated rabbit aorta in response to acetylcholine. The substance released from the endothelium to elicit relaxation was later termed "endothelium-derived relaxing factor" (EDRF). S) Since then, other investigators $^{13,43)}$ have confirmed endothelium-dependent vasodilatory responses to various agents in different preparations. One recently-identified EDRF is nitric oxide or a closely related substance. ${ }^{33)}$

In certain blood vessels, the presence of endothelium is also required for the contractile response to stimulation by various chemicals, such as norepinephrine, ${ }^{9)}$ thrombin, ${ }^{9)}$ acetylcholine, ${ }^{3,22,25)}$ arachidonic acid, ${ }^{22)}$ serotonin, ${ }^{24)}$ neuropeptide $Y{ }^{8)}$ and calcium ionophore A23187. ${ }^{22)}$ Mechanical stretch-

Received March 13, 1989; Accepted September 26, 1989 ing, ${ }^{21)}$ increased transmural pressure, ${ }^{15)}$ and anox$\mathrm{ia}^{10,37)}$ can also cause endothelium-dependent contractions. These findings suggest the existence of a diffusible vasoconstrictor substance, specifically, "endothelium-derived constricting factor" (EDCF). The EDCF candidates include prostanoids ${ }^{29,42)}$ and peptides. ${ }^{16,32)}$ Recently, Yanagisawa et $a .^{45)}$ isolated a potent vasoconstrictive peptide, endothelin, from the culture supernatant of porcine aortic endothelium, determined its amino acid sequence, and showed that it is one of the most potent vasoconstrictors in the blood vessels of many mammals.

Subarachnoid hemorrhage (SAH) results in various degrees of endothelial damage to the cerebral arteries, including vacuolation and denudation of the endothelial cells, ${ }^{1,12,38,41)}$ and it has been suggested that impairment of vasodilation due to endothelial damage may play an important role in the pathogenesis of vasospasm following $\mathrm{SAH}^{23,26,30,34,39,44)}$ Arterial wall prostacyclin, a powerful vasodilator, decreases progressively following $\mathrm{SAH},{ }^{26,39,44)}$ and en- 
dothelium-dependent vasodilation is also impaired following SAH. ${ }^{18,23,30,34)}$

It is possible that endothelial damage caused by SAH also affects endothelium-dependent vasocontraction. Production or release of endothelin might be stimulated in slightly injured endothelial cells following SAH. Permeation of endothelin into the smooth muscle layer is facilitated by disruption of the blood-arterial wall barrier following $\mathrm{SAH},{ }^{39)}$ which could induce prolonged contraction of the major cerebral arteries. Therefore, investigation of the pathogenesis of vasospasm requires evaluation of the effect of endothelin on the major cerebral arteries. The aim of this investigation was to evaluate the vasoconstricting activity of endothelin in canine basilar arteries in vitro.

\section{Materials and Methods}

\section{Preparation of arteries}

Adult mongrel dogs of both sexes, weighing 9-14 $\mathrm{kg}$, were anesthetized with sodium pentobarbital ( 30 $\mathrm{mg} / \mathrm{kg}$ ) and sacrificed by exsanguination from the femoral artery. These procedures were conducted in accordance with National Institute of Health guidelines for animal care and handling. The brain, with the basilar artery in situ, was removed and placed in a dissecting chamber filled with a modified Krebs bicarbonate solution $(\mathrm{NaCl} 120 \mathrm{mM}, \mathrm{KCl} 4.5 \mathrm{mM}$, $\mathrm{MgSO}_{4} 1.0 \mathrm{mM}, \mathrm{NaHCO}_{3} 27.0 \mathrm{mM}, \mathrm{KH}_{2} \mathrm{PO}_{4} 1.0$ $\mathrm{mM}, \mathrm{CaCl}_{2} 2.5 \mathrm{mM}$, and dextrose $10.0 \mathrm{mM}$ ). The basilar artery was dissected free under magnification and ring segments $4 \mathrm{~mm}$ in length were prepared. The outer diameters of the basilar arteries were 0.8 $1.2 \mathrm{~mm}$. Each specimen was suspended between Lshaped stainless steel rods in a siliconized organ bath with a $10 \mathrm{ml}$ working volume, which was bubbled with $95 \% \mathrm{O}_{2} / 5 \% \mathrm{CO}_{2}$. The $\mathrm{pH}$ of the solution ranged from 7.4 to 7.5 . The preparations were allowed to equilibrate at $37^{\circ} \mathrm{C}$ for 90 minutes before use. The resting tension was adjusted to $1.0 \mathrm{gm}$. Contractile force was recorded isometrically with a force-displacement transducer (model WT-611T; Nihon Koden, Tokyo, Japan) and displayed on a chart recorder (model CDR-12A; Toa Electronics Ltd., Tokyo, Japan).

Each arterial ring was exposed to $40 \mathrm{mM} \mathrm{KCl}$ and, after confirmation of a consistent contractile response to $\mathrm{KCl}$ followed by repeated washings, experiments with endothelin were begun. The contractile response to endothelin was expressed as a percentage of the contraction elicited by $40 \mathrm{mM} \mathrm{KCl}$. First, the concentration-response curve for endothelin was obtained for canine basilar arteries by cumulative addition. For comparison, canine mesenteric and femoral arteries were also prepared for this experiment. Ring segments $4 \mathrm{~mm}$ in length were cut from both, the outer diameters being $1.3-1.8 \mathrm{~mm}$ for the mesenteric and 3.4-4.0 $\mathrm{mm}$ for the femoral arteries. The basal tension was adjusted to $2.5 \mathrm{gm}$ for the mesenteric and $4.0 \mathrm{gm}$ for the femoral arteries.

The second experiment was designed to determine whether or not the contractile response to endothelin is altered by the removal of endothelial cells. The basilar artery attached to the brainstem was cut in cross section, and one half was used for control studies with intact endothelium. The other half was de-endothelialized by the following procedure. A no. 30 needle connected to a gas supply delivering $95 \% \mathrm{O}_{2} / 5 \% \mathrm{CO}_{2}$ was introduced into one end of the basilar artery. A gentle stream of gas was passed through the lumen of the vessel for 10 minutes to produce a drying injury of the endothelium. The vascular lumen was then reperfused with Krebs solution containing $10^{-4} \mathrm{M}$ papaverine to reverse the contraction induced by the above procedure. The specimen was placed in normal Krebs solution, and endothelial cells were removed by gentle rubbing with a polyethylene tube (PE20). The integrity of the endothelium was confirmed by relaxation in response to thrombin during contraction with $10^{-6} \mathrm{M}$ prostaglandin $\mathrm{F}_{2 \alpha}\left(\mathrm{PGF}_{2 \alpha}\right)$.

The third experiment was designed to evaluate the influence of extracellular calcium on endothelin-induced contraction of canine basilar artery. The preparations were exposed to a $\mathrm{Ca}^{\text {H}}$-free medium containing $1 \mathrm{mM}$ ethylene glycol-bis $(\beta$-aminoethyl ether)-N,N'-tetra-acetic acid (EGTA) for 15 minutes. Next, $10^{-8} \mathrm{M}$ endothelin was added, and 10 minutes later $2.5 \mathrm{mM} \mathrm{CaCl}_{2}$ was added. For comparison, the same experiment was conducted without endothelin, under $\mathrm{Ca}^{+}$-free conditions.

In a fourth experiment, the effects of papaverine $\left(10^{-5}\right.$ and $\left.10^{-4} \mathrm{M}\right)$ and nicardipine $\left(10^{-8} \mathrm{M}\right)$, a calcium channel blocker, were evaluated with respect to the contraction induced by $10^{-8} \mathrm{M}$ endothelin. Preparations were also exposed to nicardipine $\left(10^{-8}\right.$ $10^{-6} \mathrm{M}$ ) for 15 minutes before the cumulative addition of endothelin.

Finally, the effects of vasoactive agents that induce endothelium-dependent relaxation were evaluated with respect to the contraction already induced by $3 \times 10^{-9} \mathrm{M}$ endothelin. Acetylcholine $\left(10^{-7}-10^{-4}\right.$ $\mathrm{M})$, adenosine triphosphate (ATP) $\left(10^{-7}-10^{-5} \mathrm{M}\right)$, and thrombin $(0.1$ and $1.0 \mathrm{U} / \mathrm{ml})$ were then added in a cumulative fashion. In the relaxation studies with ATP, the arterial rings were pretreated with $10^{-5} \mathrm{M} 8$-phenyltheophylline, an adenosine antago- 
nist, 5 minutes before application of endothelin to exclude the effect of endothelium-independent relaxation by adenosine. The relaxation induced by these agents was expressed as a percentage of the contraction induced by $3 \times 10^{-9} \mathrm{M}$ endothelin.

\section{Drugs}

Synthetic human and porcine endothelin was generously provided by the Peptide Institute (Osaka, Japan). Acetylcholine, ATP, bovine thrombin, $\mathrm{PGF}_{2 \alpha}$, papaverine, EGTA, and 8-phenyltheophylline were obtained from Sigma Chemical Co. (St. Louis, Mo., U.S.A.). Nicardipine was provided by Yamanouchi Pharmaceutical Co. (Tokyo, Japan). For preparation of stock solutions, endothelin was dissolved in Krebs solution, and all other drugs except nicardipine were dissolved in distilled water, then diluted in Krebs solution before use. Nicardipine was dissolved in Krebs solution each day before use.

\section{Statistical analysis}

The data are expressed as means \pm SEM. The contractile responses at each concentration of endothelin was statistically compared with Student's ttest. A p value of $<0.05$ was considered statistically significant.

\section{Results}

\section{Effects of endothelin on canine basilar, mesen-} teric, and femoral arteries

The contractile responses of the canine basilar, mesenteric, and femoral arteries to the standard $\mathrm{KCl}$ dose of $40 \mathrm{mM}$ were $3.5 \pm 0.3,3.9 \pm 0.3$, and $5.7 \pm 0.6 \mathrm{gm}$, respectively. Endothelin induced contractions of these three arteries in a dose-dependent fashion (Figs. 1 and 2). The contraction of the basilar artery induced by $10^{-8} \mathrm{M}$ endothelin was long-lasting, as shown in Figs. 1 and 4A. After contracting maximally, the arterial ring gradually returned to the initial contractile level. The contractile response of the canine basilar artery to $10^{-8} \mathrm{M}$ endothelin lasted for more than 1 hour $(n=6)$. The estimated concentration at $50 \%$ contraction $\left(\mathrm{EC}_{50}\right)$ for the basilar, mesenteric, and femoral arteries were $(2.1 \pm 0.5) \times 10^{-9},(1.4 \pm 0.3) \times 10^{-9}$, and $(3.0 \pm$ $0.5) \times 10^{-9} \mathrm{M}$, respectively. There was no significant difference between these three $\mathrm{EC}_{50}$ values. The minimal concentration of endothelin that resulted in contraction of the basilar artery was $10^{-12} \mathrm{M}$; it was higher for the mesenteric and femoral arteries. The maximal contractile response of the basilar artery to endothelin was much larger than that induced by 40

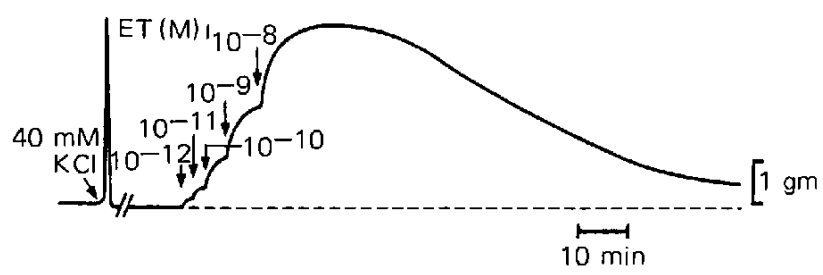

Fig. 1 Representative tracing of the effect of endothelin (ET) on canine basilar artery. Endothelin $\left(10^{-12}-10^{-8} \mathrm{M}\right)$ induced strong contraction in a dose-dependent fashion. After contracting maximally, the arterial ring gradually returned to the initial contractile level.

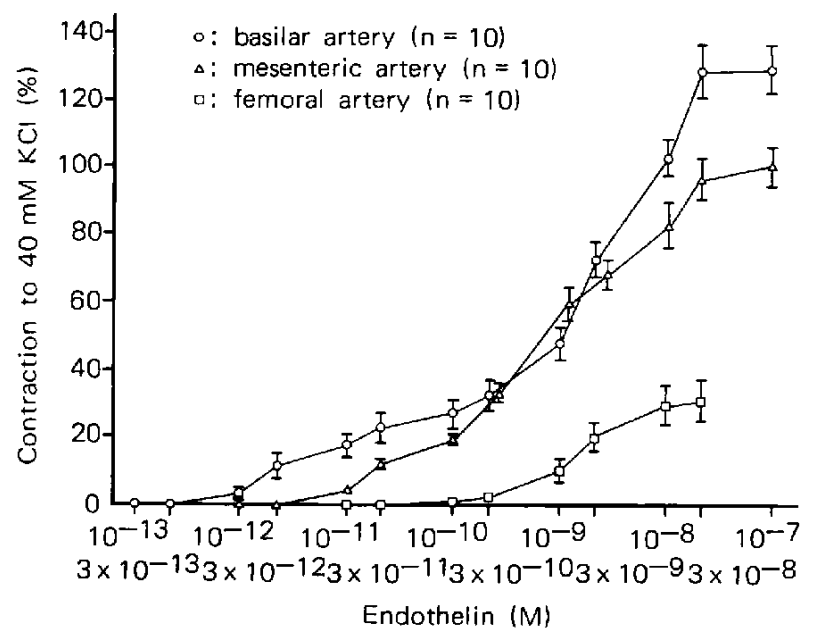

Fig. 2 Concentration-response curves to endothelin for canine basilar, mesenteric, and femoral arteries. The minimal concentration of endothelin that produced contraction of the basilar artery was $10^{-12} \mathrm{M}$. The maximal contractile response of the basilar artery to endothelin was not only much larger than that induced by $40 \mathrm{mM} \mathrm{KCl}$, but also was larger than that of the mesenteric or femoral arteries. $n$ : number of animals studied.

$\mathrm{mM} \mathrm{KCl}$. When the maximal endothelin-induced contractions of each of these arteries were compared with the contractions induced by the standard dose of $\mathrm{KCl}$, the basilar artery showed greater contraction in response to endothelin than either the mesenteric or femoral artery. However, the maximal contractile responses of the basilar and mesenteric arteries were not significantly different.

II. Effect of removal of the endothelium on en-
dothelin-induced contraction Contractions to $40 \mathrm{mM} \mathrm{KCl}$ were not significantly 
different between the preparations with and without endothelium. Removal of the endothelium significantly $(p<0.05)$ shifted the concentrationresponse curve to endothelin to the left in canine basilar artery (Fig. 3). In de-endothelialized arterial rings, endothelin at a concentration of $10^{-13} \mathrm{M}$ produced contraction.

\section{Effect of $\mathrm{Ca}^{+}$-free medium on endothelin-in- duced contraction}

Endothelin at a dose of $10^{-8} \mathrm{M}$ induced potent contraction of canine basilar artery in normal Krebs solution (Fig. 4A). In a $\mathrm{Ca}^{+}$-free medium containing 1 mM EGTA, no contraction of the basilar artery was

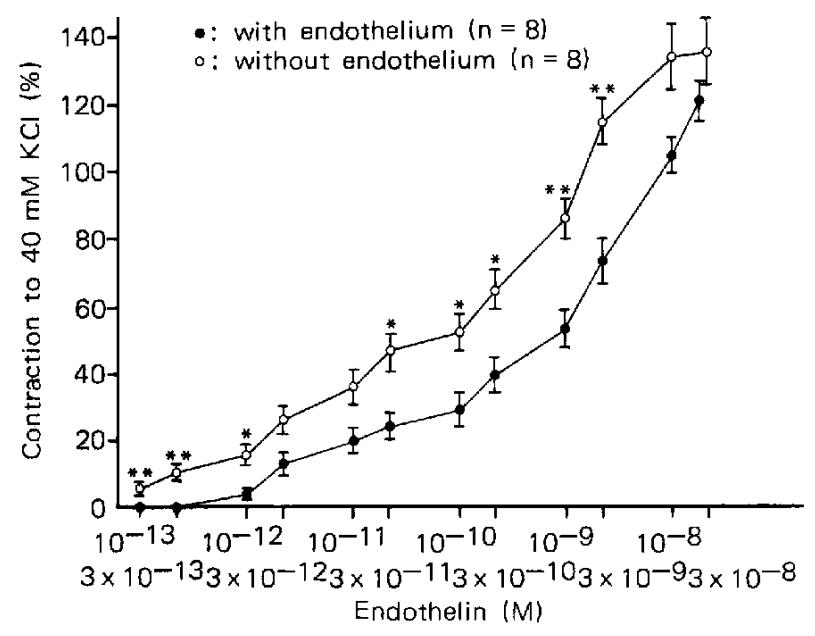

Fig. 3 Concentration-response curves to endothelin for canine basilar artery. The curve shifted significantly to the left after removal of endothelium. $\mathrm{n}$ : number of animals studied. ${ }^{*} \mathrm{p}<0.05,{ }^{* *} \mathrm{p}<0.01$ vs. with endothelium. elicited by $10^{-8} \mathrm{M}$ endothelin $(\mathrm{n}=6)$ (Fig. 4B). The addition of $2.5 \mathrm{mM} \mathrm{CaCl}_{2}$, in the absence of endothelin, induced phasic contraction of the basilar artery (Fig. 4C). The arterial rings exposed to $10^{-8} \mathrm{M}$ endothelin for 10 minutes in a $\mathrm{Ca}^{\mathrm{H}}$-free medium showed, upon re-addition of $2.5 \mathrm{mM} \mathrm{CaCl}_{2}$, larger contractions than those not exposed to endothelin $(n=6)$ (Fig. 4B).

\section{Effect of papaverine and nicardipine on en- dothelin-induced contraction}

Papaverine $\left(10^{-5}\right.$ and $\left.10^{-4} \mathrm{M}\right)$ caused vasodilation of the canine basilar arteries in a dose-dependent fashion during contraction to $10^{-8} \mathrm{M}$ endothelin (Fig. 5A, B). Nicardipine $\left(10^{-8} \mathrm{M}\right)$ also induced vasodilation of the basilar artery pre-contracted with $10^{-8} \mathrm{M}$ endothelin (Fig. 5C). The inhibition by both papaverine and nicardipine of endothelin-induced contraction was nearly absolute. The inhibitory effect of papaverine was noted just after its addition (Fig. 5A). The action of nicardipine, however, was weaker, and it took more than 1 hour for the basilar artery to relax to the baseline value (Fig. 5C). The results were the same at higher doses of nicardipine $\left(10^{-7}\right.$ and $\left.10^{-6} \mathrm{M}\right)$ (data not shown). Pretreatment with nicardipine $\left(10^{-8}-10^{-6} \mathrm{M}\right)$ significantly and dose-dependently inhibited endothelin-induced contraction of canine basilar artery (Fig. 6). Moderate contractions of the artery persisted at higher concentrations of endothelin.

\section{Effects of acetylcholine, ATP, and thrombin on endothelin-induced contraction}

Acetylcholine $\left(10^{-7}-10^{-4} \mathrm{M}\right)$ induced only slight relaxation in canine basilar artery pre-contracted by $3 \times 10^{-9} \mathrm{M}$ endothelin, in a dose-dependent fashion
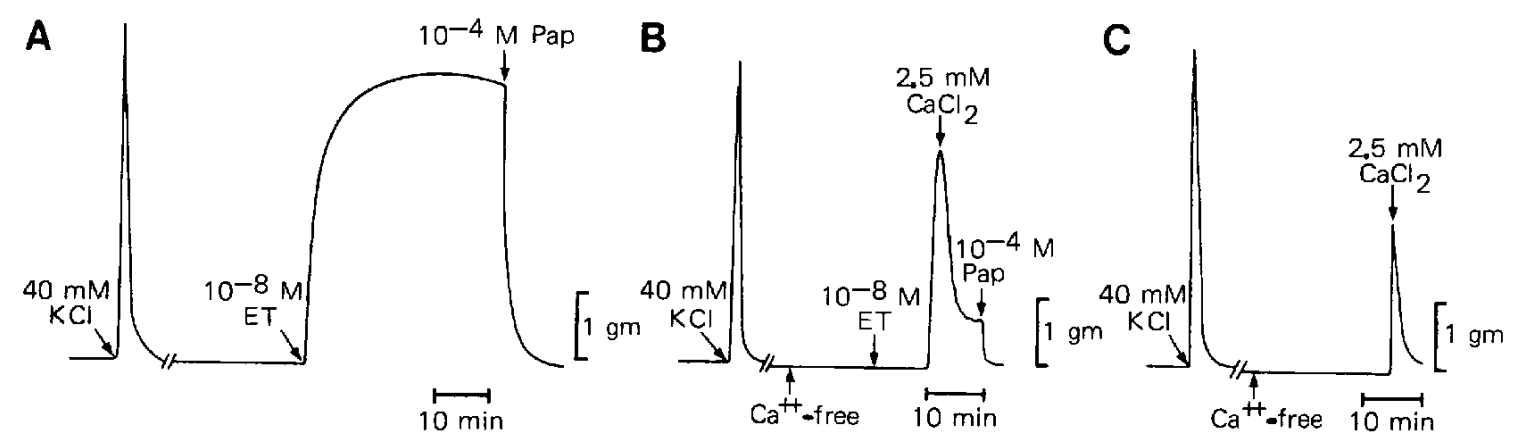

Fig. 4 Representative tracings of the contraction induced by $10^{-8} \mathrm{M}$ endothelin (ET) in normal (A) and in a $\mathrm{Ca}^{H}$-free medium containing $1 \mathrm{mM}$ EGTA (B). No contractile response to endothelin was elicited in $\mathrm{Ca}^{+}$-free medium. Addition of $2.5 \mathrm{mM} \mathrm{CaCl}$ caused phasic contraction of the basilar artery without endothelin (C). Re-addition of $2.5 \mathrm{~m} \mathrm{M} \mathrm{CaCl}_{2}$ induced larger contractions in the basilar arteries with $10^{-8} \mathrm{M}$ endothelin than in those without endothelin. Pap: papaverine. 

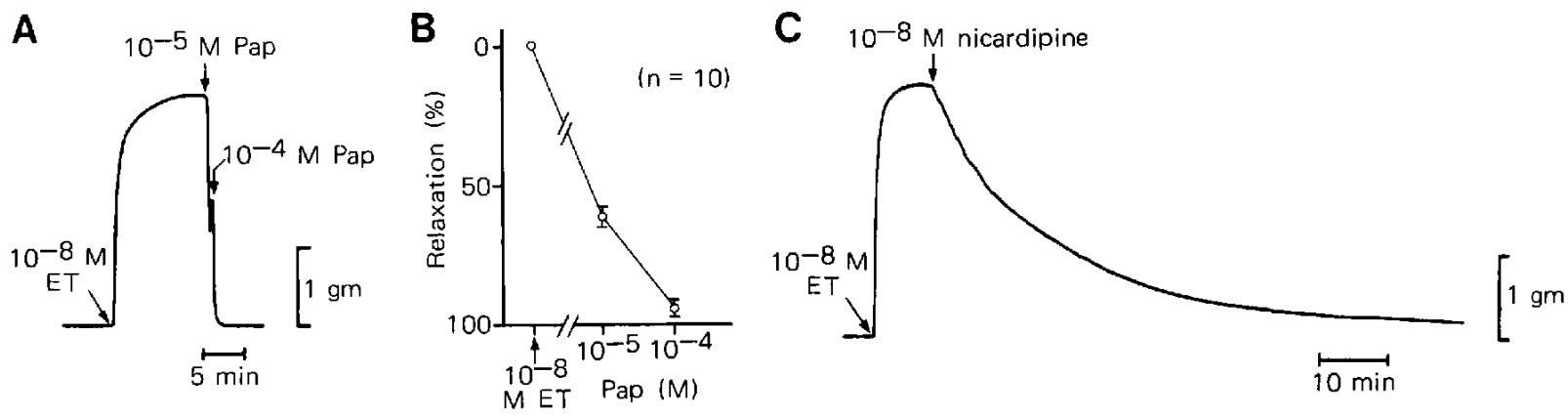

Fig. 5 Representative tracings of the effect of papaverine (Pap) (A) and nicardipine (C), a calcium channel blocker, on endothelin (ET)-induced contraction of the canine basilar artery, and concentration-response curve to papaverine (B). Papaverine $\left(10^{-4} \mathrm{M}\right)$ and nicardipine $\left(10^{-8} \mathrm{M}\right)$ almost completely reversed the contraction induced by $10^{-8} \mathrm{M}$ endothelin. $\mathrm{n}$ : number of animals studied.

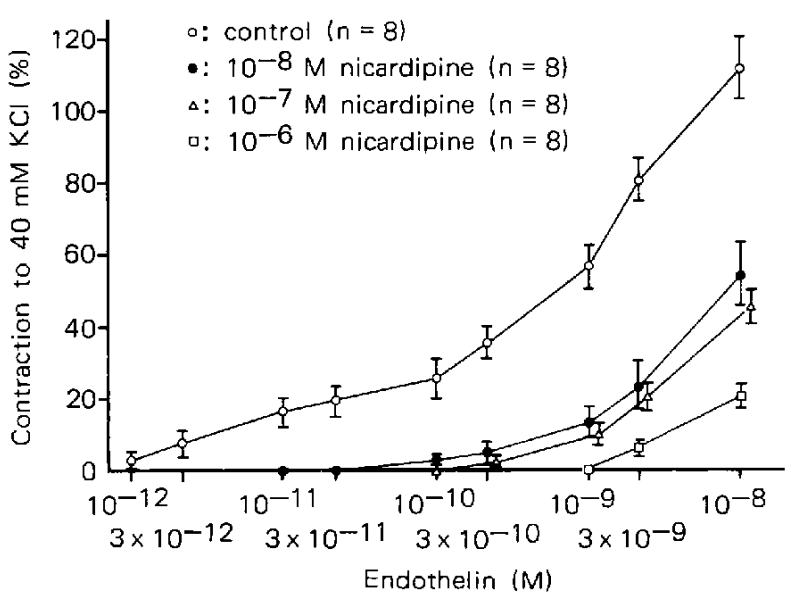

Fig. 6 Effect of nicardipine pretreatment on the contractile response of canine basilar artery to endothelin. Nicardipine pretreatment significantly suppressed the response to endothelin. n: number of animals studied.

(Fig. 7A). ATP and thrombin also induced dosedependent relaxation of the basilar artery pre-contracted by $3 \times 10^{-9} \mathrm{M}$ endothelin (Fig. 7B, C). The maximal relaxations of the basilar artery to $10^{-4} \mathrm{M}$ acetylcholine, $10^{-5} \mathrm{M}$ ATP, and $1.0 \mathrm{U} / \mathrm{ml}$ thrombin were $16.1 \pm 4.3 \%, 71.7 \pm 5.1 \%$, and $84.9 \pm 5.0 \%$, respectively.

\section{Discussion}

The results of this study demonstrate that endothelin has a potent, long-lasting constricting effect on canine basilar artery. The $\mathrm{EC}_{50}$ was $(2.1 \pm 0.5) \times$ $10^{-9} \mathrm{M}$. Moreover, the minimal concentration required for contraction of the normal canine basilar artery was extremely low $\left(10^{-12} \mathrm{M}\right)$. The maximal contractile response to endothelin was much greater than that induced by $40 \mathrm{mM} \mathrm{KCl}$. Thus, endothelin is one of the most potent vasoconstrictors known.

No contractile response was elicited at $10^{-8} \mathrm{M}$ endothelin in $\mathrm{Ca}^{++}$-free medium, and nicardipine, at a concentration of $10^{-8} \mathrm{M}$, almost completely reversed the contraction induced by $10^{-8} \mathrm{M}$ endothelin. Nicardipine pretreatment $\left(10^{-8}-10^{-6} \mathrm{M}\right)$ also significantly suppressed the contractile response to endothelin. These results suggest that extracellular $\mathrm{Ca}^{+}$plays a major role in the endothelin-mediated contraction of the canine basilar artery. However, moderate contractions were observed at higher concentrations of endothelin, and the inhibitory effect of nicardipine on endothelin-induced contraction was non-competitive. Therefore, one or more mechanisms other than the stimulation of dihydropyridine-sensitive $\mathrm{Ca}^{+}$channel may be involved in the endothelin-induced contractions of the canine basilar artery.

Removal of the arterial endothelium significantly shifted the concentration-response curve to endothelin to the left. This result is consistent with our previous results with serotonin, $\mathrm{PGF}_{2 \alpha}, \mathrm{PGE}_{2}$, and $\mathrm{PGD}_{2}$ in the canine basilar artery. ${ }^{31)}$ Enhancement of vasocontraction following removal of the endothelium appears to be a universal phenomenon, with no differences among species, anatomical site of the artery, or the vasoconstrictor agents used. ${ }^{2,4,6,7,11,23,27,31,40)}$ It has been suggested that endothelium may exert a tonic relaxing influence on the smooth muscle cells through spontaneous release of EDRF. ${ }^{15,18,28,31)}$ Abolition of EDRF release may be responsible for the enhanced vasocontraction following endothelium removal.

The endothelin-induced contraction of canine basilar artery was almost completely suppressed by 
A
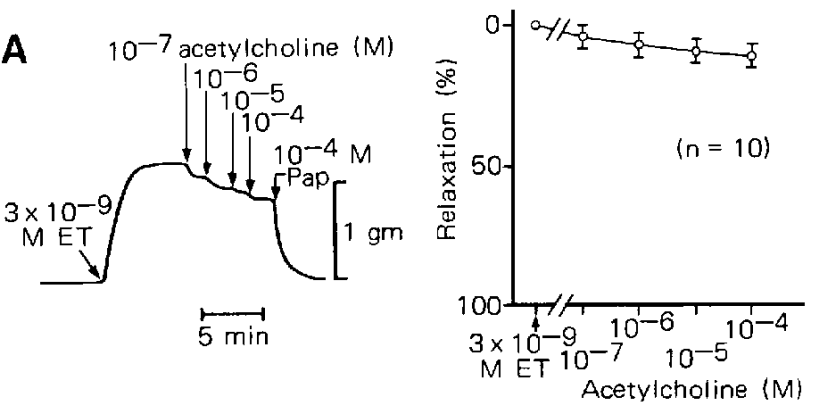

B
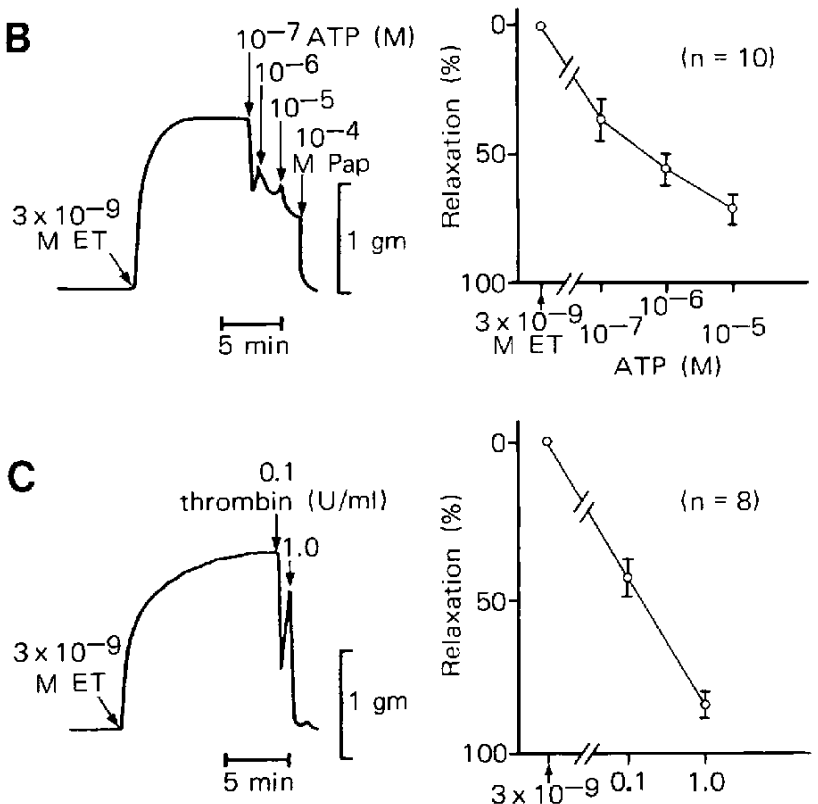

Fig. 7 Representative tracings (left) of the effect of acetylcholine (A), ATP (B), and thrombin (C) on the contraction of canine basilar artery induced by $3 \times 10^{-9} \mathrm{M}$ endothelin (ET), and concentration-response curves (right). Acetylcholine, ATP, and thrombin induced relaxation of the artery in a dose-dependent fashion. Pap: papaverine, $\mathrm{n}$ : number of animals studied.

the addition of $10^{-4} \mathrm{M}$ papaverine. Acetylcholine, ATP, and thrombin, which are known to induce endothelium-dependent relaxation, also evoked relaxation of the basilar artery pre-contracted with $3 \times$ $10^{-9} \mathrm{M}$ endothelin. The relaxation induced by these agents is associated with activation of the enzyme guanylate cyclase and an increase in the intracellular production of cyclic guanosine monophosphate. ${ }^{17,35)}$ The relaxation produced by glyceryl trinitrate is also associated with an increase in the cytoplasmic concentration of this cyclic nucleotide, ${ }^{20)}$ and has been reported to inhibit endothelin-induced vasocontrac- tion in porcine artery. ${ }^{45)}$ These observations suggest that endothelin does not affect the basic mechanism of relaxation in smooth muscle cells.

The present study demonstrated that acetylcholine induced vasodilation in the canine basilar artery, although to a minimal degree. This result is inconsistent with the finding of Katusic et al. ${ }^{22)}$ that acetylcholine induces endothelium-dependent vasocontraction. The reason for this discrepancy is unclear, but might be attributable to differences in experimental conditions or in the experimental dogs used.

Yanagisawa et ll $^{45}$ ) showed that the messenger ribonucleic acid (RNA) encoding prepro-endothelin increased rapidly when the endothelial cells were exposed to thrombin, epinephrine, or the calcium ionophore A23187. In endothelial cells cultured under flowing conditions, prepro-endothelin messenger RNA is substantially reduced. ${ }^{45)}$ These chemical and mechanical stimuli can, at the same time, induce the release of EDRF. These authors suggested that both EDRF and endothelin play an important role in the regulation of vascular smooth muscle tone.

Endothelial damage of varying degree often occurs in the major cerebral arteries following $\mathrm{SAH}$, and may include vacuolation, loss of tight junctions, and denudation of the endothelial cells..$^{1,12,30,38,41)}$ It is likely that such injury affects endothelium-dependent contraction of the artery. Endothelin is produced constitutively by endothelial cells in culture, ${ }^{45)}$ and Ross $^{36}$ hypothesized that cultured endothelium may more closely approximate an in vivo state of injury. According to his theory, production of endothelin may be stimulated in slightly injured cerebral arterial endothelial cells following SAH. In addition, disruption of the barrier of major cerebral arteries occurs following SAH, which may allow endothelin to permeate the smooth muscle layer ${ }^{38)}$ We recently found that endothelin injected into the cisterna magna caused biphasic contraction of the canine basilar artery, which lasted for more than 24 hours. ${ }^{19)}$ Therefore, it is reasonable to suspect that endothelin plays an important role, as a possible spasmogenic substance, in the pathogenesis of cerebral vasospasm following SAH. Impairment of endothelium-dependent vasodilation following SAH probably contributes to sustained constriction of the artery induced by endothelin and other vasoconstrictors.

At present, it is still unclear whether or not human cerebral arteries can produce endothelin, or if there is enough endothelin to induce prolonged arterial contraction in the cerebrospinal fluid of patients with SAH. Clarification of the role of endothelin in the 
pathogenesis of vasospasm following SAH requires more extensive study.

\section{Acknowledgment}

The authors thank Ms. Reiko Matsuura for her excellent technical assistance.

\section{References}

1) Alksne JF, Smith RW: Experimental models of spasm. Clin Neurosurg 24: 216-227, 1977

2) Allan G, Brook CD, Cambridge D, Hladkwiskyi J: Enhanced responsiveness of vascular smooth muscle to vasoconstrictor agents after removal of endothelial cells. $\mathrm{Br} J$ Pharmacol 79: 334P, 1983 (abstract)

3) Altiere RJ, Kiritsy-Roy JA, Catravas JD: Acetylcholine-induced contractions in isolated rabbit pulmonary arteries: Role of thromboxane $\mathrm{A}_{2}$. J Pharmacol Exp Ther 236: 535-541, 1986

4) Carrier GO, White RE: Enhancement of alpha-1 and alpha-2 adrenergic agonist-induced vasoconstriction by removal of endothelium in rat aorta. $J$ Pharmacol Exp Ther 232: 682-687, 1985

5) Cherry PD, Furchgott RF, Zawadzki JV, Jothianandan D: Role of endothelial cells in relaxation of isolated arteries by bradykinin. Proc Natl Acad Sci USA 79: 2106-2110, 1982

6) Cocks TM, Angus JA: Endothelium-dependent relaxation of coronary arteries by noradrenaline and serotonin. Nature 305: 627-630, 1983

7) Cohen RA, Shepherd JT, Vanhoutte PM: 5-Hydroxytryptamine can mediate endothelium-dependent relaxation of coronary arteries. Am J Physiol 245: H1077-H1080, 1983

8) Daly RN, Hieble JP: Neuropeptide $Y$ modulates adrenergic neurotransmission by an endothelium dependent mechanism. Eur J Pharmacol 138: 445446, 1987

9) De Mey JG, Vanhoutte PM: Heterogenous behavior of the canine arterial and venous wall. Importance of the endothelium. Circ Res 51: 439-447, 1982

10) De Mey JG, Vanhoutte PM: Anoxia and endothelium-dependent reactivity of the canine femoral artery, $J$ Physiol (Lond) 335: 65-74, 1983

11) Egléme C, Godfraind T, Miller RC: Enhanced responsiveness of rat isolated aorta to clonidine after removal of the endothelial cells. $\mathrm{Br} J$ Pharmacol 81 : 16-18, 1984

12) Fein JM, Flor WJ, Cohan SL, Parkhurst J: Sequential changes of vascular ultrastructure in experimental cerebral vasospasm. Myonecrosis of subarachnoid arteries. J Neurosurg 41: 49-58, 1974

13) Furchgott RF: The role of endothelium in the responses of vascular smooth muscle to drugs. Annu Rev Pharmacol Toxicol 24: 175-197, 1984

14) Furchgott RF, Zawadzki JV: The obligatory role of endothelial cells in the relaxation of arterial smooth muscle by acetylcholine. Nature 288: 373-376, 1980

15) Harder DR: Pressure-induced myogenic activation of cat cerebral arteries is dependent on intact endothelium. Circ Res 60: 102-107, 1987

16) Hickey KA, Rubanyi G, Paul RJ, Highasmith RF: Characterization of a coronary vasoconstrictor produced by cultured endothelial cells. Am J Physiol 248: C550-C556, 1985

17) Holzmann S: Endothelium-induced relaxation by acetylcholine associated with larger rises in cyclic GMP in coronary arterial strips. J Cyclic Nucleotide Res 8: 409-419, 1982

18) Hongo $K$, Kassell NF, Nakagomi $T$, Sasaki $T$, Tsukahara T, Ogawa H, Vollmer DG, Lehman RM: Subarachnoid hemorrhage inhibition of endothelium-derived relaxing factor in rabbit basilar artery. $J$ Neurosurg 69: 247-253, 1988

19) Ide $K$, Yamakawa $K$, Nakagomi $T$, Sasaki $T$, Saito $I$, Kurihara H, Yoshizumi M, Yazaki Y, Takakura K: The role of endothelin in the pathogenesis of vasospasm following subarachnoid hemorrhage. Neurol Res 11: 101-104, 1989

20) Katsuki S, Arnold WP, Murad F; Effects of sodium nitroprusside, nitroglycerin, and sodium azide on levels of cyclic nucleotides and mechanical activity of various tissues. J Cyclic Nucleotide Res 3: 239-247, 1977

21) Katusic ZS, Shepherd JT, Vanhoutte PM: Endothelium-dependent contraction to stretch in canine basilar arteries. Am J Physiol 252: H671-H673, 1987

22) Katusic ZS, Shepherd JT, Vanhoutte PM: Endothelium-dependent contractions to calcium ionophore A23187, arachidonic acid, and acetylcholine in canine basilar arteries. Stroke 19: 476-479, 1988

23) Kim P, Sundt TM Jr, Vanhoutte PM: Alterations in endothelium-dependent responsiveness of the canine basilar artery after subarachnoid hemorrhage. $J$ Neurosurg 69: 239-246, 1988

24) Lamping KG, Marcus ML, Dole WP: Removal of the endothelium potentiates canine large coronary artery constrictor responses to 5-hydroxytryptamine in vitro. Circ Res 57: 46-54, 1985

25) Lüscher TF, Vanhoutte PM: Endothelium-dependent contractions to acetylcholine in the aorta of the spontaneously hypertensive rat. Hypertension 8: 344-348, 1986

26) Maeda $Y$, Tani E, Miyamoto $T$ : Prostaglandin metabolism in experimental cerebral vasospasm. $J$ Neurosurg 55: 779-785, 1981

27) Martin W, Furchgott RF, Villani GM, Jothianandan $\mathrm{D}$ : Depression of contractile responses in rat aorta by spontaneously released endothelium-derived relaxing factor. J Pharmacol Exp Ther 237: 529-538, 1986

28) Martin W, Villani GM, Jothianandan D, Furchgott RF: Selective blockade of endothelium-dependent and glyceryl trinitrate-induced relaxation by hemoglobin and by methylene blue in the rabbit aorta. $J$ Pharmacol Exp Ther 232: 708-716, 1985

29) Miller VM, Vanhoutte PM: Endothelium-dependent 
contractions to arachidonic acid are mediated by products of cyclooxygenase. Am $J$ Physiol 248: H432-H437, 1985

30) Nakagomi T, Kassell NF, Sasaki T, Fujiwara S, Lehman RM, Torner JC: Impairment of endothelium-dependent vasodilation induced by acetylcholine and adenosine triphosphate following experimental subarachnoid hemorrhage. Stroke 18: 482489, 1987

31) Nakagomi T, Kassell NF, Sasaki T, Lehman RM, Torner JC, Hongo K, Lee JH: Effect of removal of the endothelium on vasocontraction in canine and rabbit basilar arteries. $J$ Neurosurg 68: 757-766, 1988

32) O'Brien RF, Robbins RJ, McMurtry IF: Endothelial cells in culture produce a vasoconstrictor substance. $J$ Cell Physiol 132: 263-270, 1987

33) Palmer RMJ, Ferrige AG, Moncada S: Nitric oxide release accounts for the biological activity of endothelium-derived relaxing factor. Nature 327: 524526,1987

34) Peterson JW, Bun T, Zervas NT: Plasma-borne vasoactivity and modulation by the endothelium as determinants of cerebrovascular tone: Possible role during cerebral vasospasm, in Powers WJ, Raichle ME (eds): Cerebrovascular Diseases. Fifteenth Research (Princeton) Conference. New York, Raven, 1987, pp 187-200

35) Rapoport RM, Draznin MB, Murad F: Mechanisms of adenosine triphosphate-, thrombin-, and trypsininduced relaxation of rat thoracic aorta. Circ Res 55 : 468-479, 1984

36) Ross R: The pathogenesis of atherosclerosis - an update. $N$ Engl J Med 314: 488-500, 1986

37) Rubanyi GM, Vanhoutte PM: Hypoxia releases a vasoconstrictor substance from the canine vascular endothelium. J Physiol (Lond) 364: 45-56, 1985

38) Sasaki $T$, Kassell NF, Yamashita M, Fujiwara S, Zuccarello M: Barrier disruption in the major cerebral arteries following experimental subarachnoid hemorrhage. J Neurosurg 63: 433-440, 1985

39) Sasaki T, Murota S, Wakai S, Asano T, Sano K: Evaluation of prostaglandin biosynthetic activity in canine basilar artery following subarachnoid injection of blood. $J$ Neurosurg 55: 771-778, 1981

40) Sercombe R, Verrecchia C, Oudart N, Dimitriadou $\mathrm{V}$, Seylaz J: Pial artery responses to norepinephrine potentiated by endothelium removal. J Cereb Blood Flow Metab 5: 312-317, 1985

41) Tanabe $Y$, Sakata $K$, Yamada $H$, Ito $T$, Takada $M$ : Cerebral vasospasm and ultrastructural changes in cerebral arterial wall. $J$ Neurosurg 49: 229-238, 1978

42) Usui $H$, Kurahashi $K$, Shirahase $H$, Fukui $K$, Fujiwara M: Endothelium-dependent vasocontraction in response to noradrenaline in the canine cerebral artery. Jpn J Pharmacol 44: 228-231, 1987

43) Vanhoutte PM, Miller VM: Heterogeneity of endothelium-dependent responses in mammalian blood vessels. J Cardiovasc Pharmacol 7 [Suppl] 3: S12S23, 1985

44) Walker V, Pickard JD, Smythe P, Eastwood S, Perry $\mathrm{S}$ : Effects of subarachnoid hemorrhage on intracranial prostaglandins. J Neurol Neurosurg Psychiatry 46: 119-125, 1983

45) Yanagisawa $M$, Kurihara $H$, Kimura S, Tomobe $Y$, Kobayashi M, Mitsui Y, Yazaki Y, Goto K, Masaki $\mathrm{T}$ : A novel potent vasoconstrictor peptide produced by vascular endothelial cells. Nature 332: 411-415, 1988

Address reprint requests to: T. Nakagomi, M.D., Department of Neurosurgery, Faculty of Medicine, University of Tokyo, 7-3-1 Hongo, Bunkyo-ku, Tokyo 113, Japan. 